\title{
Asylum seekers' expectations of and trust in general practice: a qualitative study
}

\author{
Catherine A O'Donnell, Maria Higgins, Rohan Chauhan and Kenneth Mullen
}

\section{ABSTRACT \\ Background}

The UK has substantial minority populations of shortterm and long-term migrants from countries with various types of healthcare systems.

Aim

This study explored how migrants' previous knowledge and experience of health care influences their current expectations of health care in a system relying on clinical generalists performing a gatekeeping role.

Design of study

Two qualitative methods.

Setting

Glasgow, UK.

\section{Method}

Focus groups or semi-structured interviews were conducted with 52 asylum seekers. Analyses identified several areas where previous experience affected current expectations. An overview of health systems in each country of origin was established by combining responders' accounts with World Health Organization statistics.

\section{Results}

Asylum seekers had previous experience of a diverse range of healthcare systems, most of which were characterised by a lack of GPs and direct access to hospital-based specialists. For some responders, war or internal conflict resulted in a complete breakdown of healthcare systems. Responders' accounts also highlighted the difficulties that marginalised groups had in accessing health care. Although asylum seekers were generally pleased with the care they received from the NHS, there were areas where they experienced difficulties: confidence in their GP and access to hospital-based specialists and medication. These difficulties encountered might be explained by previous experience.

\section{Conclusion}

GPs and other healthcare professionals need to be aware that experience of different systems of care can have an impact on individuals' expectations in a GPled system. If these are not acknowledged and addressed, a lack of confidence and trust in the GP may undermine the effectiveness of the clinical consultation.

\section{Keywords}

asylum seekers; general practice; health care needs; trust.

\section{INTRODUCTION}

The UK has a substantial minority population of short-term and long-term migrants, including 80000 asylum seekers and refugees, ${ }^{1}$ and 713000 overseas nationals working in the UK, particularly from the European Union accession countries. ${ }^{2,3}$ All are entitled to medical and dental care on the NHS, including registration with a general practice. Many migrants come from countries with no system of general practice or family medicine as is organised in the UK or other European countries such as the Netherlands. ${ }^{4}$

Asylum seekers' experience of accessing primary and secondary care in one part of the UK has previously been reported by the current authors. ${ }^{5}$ As might be expected, communication and language difficulties were an issue, although access to interpreters was much better in primary than in secondary care. Access to dentists was variable, with most only using dentists at times of clinical need rather than for routine check-ups. The asylum seekers interviewed were often unsure of how the NHS worked; for example, referrals to secondary care and waiting lists were a surprise to many, and

CA O'Donnell, BSc(Hons), MPH, PhD, FHEA, senior lecturer in primary care R\&D; $M$ Higgins, RGN, BA, PD Dip Dance Music Therapy, research fellow; $R$ Chauhan, BDS, MSc DPH, Dip DPH, research fellow, General Practice and Primary Care; K Mullen, MA, MLitt, PhD, lecturer in behavioural science, Psychological Medicine, Division of Community-based Sciences, University of Glasgow, Scotland.

Address for correspondence

Dr Catherine O’Donnell, General Practice and Primary Care, Division of Community-based Sciences, Faculty of Medicine, 1 Horselethill Road, Glasgow G12 9LX, Scotland. E-mail: Kate.O’Donnell@clinmed.gla.ac.uk

Submitted: 27 September 2007; Editor's response: 2 January 2008; final acceptance: 22 May 2008.

(c)British Journal of General Practice.

This is the full-length article of an abridged version published in print. Cite this article as: Br J Gen Pract 2008; DOI: 10.3399/bjgp08X376104. 
their previous experience of different healthcare systems appeared to affect their understanding and expectations of the NHS.

Unmet expectations are associated with decreased satisfaction with daytime ${ }^{6,7}$ and out-ofhours care, ${ }^{8,9}$ prescribing, ${ }^{10}$ and referral decisions in the general population. ${ }^{11}$ Other studies, as well as that of the present authors, ${ }^{5}$ show that asylum seekers and refugees have different expectations of health care, including a lack of awareness of appointment systems, unrealistic expectations of access to high-tech medicine, such as magnetic resonance imaging (MRI), and easier access to antibiotics. ${ }^{5,12-15}$ However, the role of previous healthcare systems in shaping these expectations has been largely unexplored.

Understanding how previous experience influences expectations is important for GPs and other healthcare professionals, as it may help to alleviate potential misunderstandings and build trust between patients and practitioners during the consultation. This building of trust is important, not only for the outcome of individual consultations, but also because it may engender trust in the healthcare system as a whole. ${ }^{16-18}$

This paper reports on how asylum seekers' previous knowledge and experience of health care in their country of origin has an impact on their expectations of general practice in the UK and their trust of GPs.

\section{METHOD}

\section{Setting}

Two qualitative studies were conducted in Glasgow, Scotland, a country which has received asylum seekers under the UK government's dispersal policy since 2000. Two areas were selected, both with substantial numbers of asylum seekers living in the area. These studies are described in detail elsewhere. ${ }^{5}$

\section{Recruitment and sampling}

Recruitment was conducted through communitybased groups working with asylum seekers, as previously described. ${ }^{5}$ Following short talks at meetings attended by asylum seekers at community-based groups or drop-in centres, individuals expressing an interest in participating received written materials (in their own language, where possible) explaining the purpose of the study. These individuals were then followed up, and those who agreed were recruited into the study.

Sampling was purposive, in that the research was located within two areas that were housing asylum seekers from a variety of countries of origin. However, due to their vulnerability and understandable reluctance to divulge personal

\section{How this fits in}

Asylum seekers, refugees, and other long-term migrants are known to have different expectations of health care and healthcare systems, particularly when

faced with a gatekeeper system such as the UK NHS. Using qualitative

approaches and official statistics to establish an overview of the healthcare

systems in responders' countries of origin, this study explored how asylum

seekers' previous experience of health care influenced their expectations of care

in the UK, particularly of general practice. Responders generally had no prior

experience of GPs and were used to direct access to hospital specialists. They

experienced difficulties in understanding the gatekeeper role of the GP and this

affected their confidence and trust in the GP. GPs and other healthcare

professionals need to be aware of these underlying expectations to avoid

undermining the effectiveness of the clinical consultation.

details, it is difficult to find or access lists of asylum seekers that give their age, sex, or country of origin. Therefore, it was not possible to purposively recruit on the basis of such characteristics. Participants were at varying stages of the asylum-seeking process, with a few having reached full refugee status. This population is referred to throughout the current paper as 'asylum seekers'. Once recruited, participants had any travel expenses reimbursed, and a light lunch or supper was provided after the focus groups; however, no one was paid a fee for participating.

\section{Data collection}

Two methods of data collection were employed: the

\section{Table 1. Responders' countries of origin. ${ }^{5}$}

\begin{tabular}{ll} 
Region $^{\text {a }}$ & Number of responders \\
\hline African region & 1 \\
Algeria & 7 \\
Democratic Republic of Congo & 1 \\
Republic of Guinea & 1 \\
Zimbabwe & \\
\hline Eastern Mediterranean region & 2 \\
Afghanistan & 4 \\
Iran & 1 \\
Lebanon & 1 \\
Morocco & 1 \\
Pakistan & 8 \\
Somalia & 1 \\
Syrian Arab Republic & \\
\hline European region & 1 \\
Albania & 1 \\
Azerbaijan & 7 \\
Russian Federation & 7 \\
Turkey & \\
\hline South-East Asia region & 8 \\
Sri Lanka
\end{tabular}

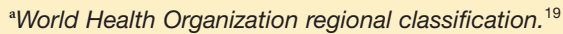


first study used focus groups facilitated by members of the asylum-seeking community; the second used one-to-one or group interviews, conducted through an interpreter. Responders' countries of origin are detailed in Table 1; demographics of the participants are reported elsewhere. ${ }^{5}$

Focus group topic guides and interview schedules were developed following a review of the literature and previous research. The guides covered a range of topics including asylum seekers' use of health services; barriers and facilitators to accessing care; use of secondary care services; experience of translators; and previous experience of health care in responders' country of origin.

Six focus groups were conducted between November 2003 and May 2004, each with five to eight participants and lasting 1.5 to 2 hours. These were facilitated by members of the asylum-seeking community, assisted by one of the researchers, and constructed according to similarities in ethnicity (for example, Turkish group) or language (for example, Farsi group). Language groups covered by these focus groups were: Farsi, Turkish, French, and Lingala (an African language spoken in the Democratic Republic of Congo), Swahili (for the Somali group), and Russian. One all-women group was conducted in English by one of the researchers assisted by a facilitator.

Sixteen individuals were interviewed from May to August 2005 by a researcher: nine one-to-one interviews and two group interviews, the first with four participants and the second with three members of the same family. All but one were conducted through an interpreter. Interviews lasted about an hour and were conducted at a venue chosen by the interviewee. The concept of written consent was explained to all participants before the focus group or interview commenced, and consent was obtained. Focus groups and interviews were terminated when it became clear, during analyses, that the same broad issues were being identified.

\section{Analyses}

Focus groups and interviews were taped and transcribed verbatim, with focus group facilitators translating where necessary. Analysis was facilitated using the framework method. ${ }^{20} \mathrm{~A}$ constant comparative approach was used throughout, whereby the codes and transcripts were continually re-assessed and re-interpreted. ${ }^{21}$ Identified themes were compared across the data, and interpretations discussed within the team. In the case of focus group transcripts, analysis sessions were also held with the facilitators to enhance the research team's understanding and interpretation of the data. Identified themes in the focus groups and interviews were compared, again to identify common and discrepant themes. Six major themes were identified and are fully presented elsewhere. ${ }^{5}$ Previous healthcare/health system experience was an overarching theme, emerging in several places during data analyses.

\section{Description of health systems in the countries of origin}

The qualitative findings provided a narrative description of the types of healthcare systems that asylum seekers were used to in their countries of origin. Using data on a variety of indicators from the World Health Organization (WHO), ${ }^{19}$ the key features of the healthcare systems of these countries were then identified; for example, the size of the healthcare workforce per head of population; government and private spending on health care; and provision of hospital beds (Table 2). An overview could then be built up of the health systems in each country of origin by combining participants' personal views of previous health care with routinely available statistics.

\section{RESULTS}

A total of 52 individuals participated in the research: 16 participated in one-to-one or group interviews; the remaining 36 participated in one of six focus groups. Responders came from 16 different countries (Table 1). Their ages ranged from 20 to 57 years; 31 were female, 21 male; and most had been in the UK for at least 3 years.

Responders were asked how the healthcare system in their country of origin compared with that in the UK. Following from this, analysis identified three areas where previous health-system experience had a particular impact.

\section{Comparison of country of origin's health systems with the NHS}

In general, all responders compared the UK NHS favourably with healthcare systems in their own countries. This was particularly true for responders from war areas, such as Afghanistan, Sri Lanka, and Somalia, where health care had all but disappeared:

'... telling you the truth, the services [here] are great but back home there are no services.' (N, female, Somali focus group)

For some, in particular Sri Lankan Tamils, internal conflict and discrimination meant that a relatively 


\begin{tabular}{|c|c|c|c|c|c|c|c|c|c|}
\hline \multirow[b]{2}{*}{ Region $^{a}$} & \multicolumn{2}{|c|}{$\begin{array}{l}\text { Number of healthcare } \\
\text { professionals per } \\
1000 \text { population }\end{array}$} & \multicolumn{2}{|c|}{$\begin{array}{l}\% \text { Immunisation } \\
\text { coverage among } \\
1 \text { year olds }\end{array}$} & \multirow[t]{2}{*}{$\begin{array}{c}\text { Total expenditure } \\
\text { on health as a } \% \\
\text { of gross domestic } \\
\text { product }\end{array}$} & \multirow[t]{2}{*}{$\begin{array}{l}\text { Government } \\
\text { spend on health } \\
\text { as \% of total } \\
\text { spend on health }\end{array}$} & \multirow[t]{2}{*}{$\begin{array}{l}\text { Private spend } \\
\text { on health as \% } \\
\text { of total spend } \\
\text { on health }\end{array}$} & \multirow[t]{2}{*}{$\begin{array}{l}\text { Hospital } \\
\text { beds } \\
\text { per } 10000\end{array}$} & \multirow[t]{2}{*}{$\begin{array}{c}\text { Gross nationa } \\
\text { income per } \\
\text { capita (\$US) }\end{array}$} \\
\hline & Physicians & Nurses & Measles & DTP3 & & & & & \\
\hline \multicolumn{10}{|c|}{ African region } \\
\hline Algeria & 1.13 & 2.21 & 81 & 86 & 4.1 & 80.8 & 19.2 & - & 6260 \\
\hline $\begin{array}{r}\text { Democratic } \\
\text { Republic } 0\end{array}$ & 0.11 & 0.53 & 64 & 64 & 4.0 & 18.3 & 81.7 & - & 680 \\
\hline Guinea & 0.11 & 0.55 & 73 & 69 & 5.4 & 16.6 & 83.4 & - & 2130 \\
\hline Zimbabwe & 0.16 & 0.72 & 80 & 85 & 7.9 & 35.9 & 64.1 & - & 2180 \\
\hline \multicolumn{10}{|c|}{ Eastern Mediterranean region } \\
\hline Afghanistan & 0.19 & 0.22 & 61 & 66 & 6.5 & 39.5 & 60.5 & 4 & - \\
\hline Iran & 0.45 & 1.31 & 96 & 99 & 6.5 & 47.3 & 52.7 & 16 & 7550 \\
\hline Lebanon & 3.25 & 1.18 & 96 & 92 & 10.2 & 29.3 & 70.7 & 30 & 5380 \\
\hline Morocco & 0.51 & 0.78 & 95 & 97 & 5.1 & 33.1 & 66.9 & 9 & 4100 \\
\hline Pakistan & 0.74 & 0.46 & 67 & 65 & 2.4 & 27.7 & 72.3 & 7 & 2160 \\
\hline Somalia & 0.04 & 0.19 & 40 & 30 & - & - & - & 4 & - \\
\hline $\begin{array}{c}\text { Syrian Arab } \\
\text { Republic }\end{array}$ & 1.40 & 1.94 & 98 & 99 & 5.1 & 48.2 & 51.8 & 15 & 3550 \\
\hline \multicolumn{10}{|c|}{ European region } \\
\hline Albania & 1.31 & 3.62 & 96 & 97 & 6.5 & 41.7 & 58.3 & 30 & 5070 \\
\hline Azerbaijan & 3.55 & 7.11 & 98 & 96 & 3.6 & 23.8 & 76.2 & 83 & 3830 \\
\hline $\begin{array}{l}\text { Russian } \\
\text { Federation }\end{array}$ & 4.25 & 8.05 & 98 & 97 & 5.6 & 59.0 & 41.0 & 99 & 9620 \\
\hline Turkey & 1.35 & 1.70 & 81 & 85 & 7.6 & 71.6 & 28.4 & 26 & 7680 \\
\hline \multicolumn{10}{|c|}{ South-East Asia region } \\
\hline Sri Lanka & 0.55 & 1.58 & 96 & 97 & 3.5 & 45.0 & 55.0 & 29 & 4000 \\
\hline \multicolumn{10}{|l|}{ Comparators } \\
\hline UK & 2.30 & 12.12 & 81 & 90 & 8.0 & 85.7 & 14.3 & 40 & 31460 \\
\hline Ireland & 2.79 & 15.20 & 81 & 89 & 7.3 & 78.9 & 21.1 & 35 & 33170 \\
\hline US & 2.56 & 9.37 & 93 & 96 & 15.2 & 44.6 & 55.4 & 33 & 39710 \\
\hline
\end{tabular}

${ }^{a}$ World Health Organization regional classification. ${ }^{19}{ }^{\mathrm{b}}$ The percentage of total health spend coming from national and local government. ${ }^{21}{ }^{\mathrm{c}}$ The percentage of total health spend coming from by private entities, including health insurance providers, non-profit making institutions, and direct household out-of-pocket payments. DTP = three-dose diphtheria, tetanus toxoid, and pertussis vaccine. ${ }^{19}$

well-organised health service located in the Sinhalese area of Sri Lanka was inaccessible to them:

'[We] are from the north of Sri Lanka, north of Sri Lanka the civil war, we have been bombed and shelled etc, so there is only a primitive health service. So because of the continuing war in the north we don't get any medicine. Everything has to come from the capital Colombo, there is no transport, no doctors, no food - that is the problem.' (R1, male, Sri Lanka, interview)

'It is a war area [Jafna], there is constantly bombing and shelling so there [is] no medical service. When they came to Colombo it had good medical services but the ethnic Sinhalese are the majority and the Tamils are the minority so there was racial discrimination.' (R13-R15, females, Sri Lanka, group interview)
Those from countries with more developed health systems (for example, Syria, the Russian Federation, Azerbaijan, and Iran) were more cautious. While they were positive about health care in the UK, many were used to accessing a hospitalbased specialist immediately, providing they paid, and felt that they had good healthcare systems in their own countries:

'... expectations are different, coming from different countries. Sometimes very poor countries have got health systems and some countries are strong countries, like Turkey, like in some cases Iran, they have very good doctors, very, very good doctors.' (R3, male, Iran, interview)

'... in Iran all the villagers get free treatment but most people live in cities and towns and they should pay, depends on whether they had any 
insurance cover. They should pay 10 or $20 \%$ for their treatment and some should pay $100 \%$ if they don't have insurance. Like a private sector but then if you want to be seen by a consultant you don't need to go through a GP, we don't have the referral system that you've got here and I think that is something good ...' (R4, male, Iran, interview)

However, access to health care was problematic for the poorest in most countries. Thus, the concept of free health care for all was welcomed:

'... back home [in Somalia] only those who have money get better medical services but if you are poor you end up using home-made medicine.' (S, female, Somali focus group)

'... anyone who doesn't have the money, they will probably die, but this here is for everyone ...' (R6, female, Syria, interview)

'I mean in Turkey even if you've got money, you still suffer if you need health care. But in this country, if you have no money you still get looked after. That system is quite good in this country.' $(\mathrm{H}$, male, Turkish focus group)

Some had no experience of a healthcare system that used GPs as a first point of contact:

SD: '... I hadn't even heard the word GP before you know! [laughter in group].'

SM: 'No it was all new to me also, so it was fine I had this visit!' [from an asylum-seeker support nurse]

SD: 'Yes, it's completely different.'

(SD, female, African; SM, female, Morocco, women's focus group)

None of the participants had experienced an appointment system to see a doctor in participants' countries of origin. This ready access to health care, even if they had to pay, meant that most felt that, when unwell, they needed to see a GP immediately:

'When I needed an emergency appointment I couldn't get one. They just wouldn't give me one. I had to go back the following day.' (L, female, Farsi focus group)

C: 'Well, I've heard that a lot of people go to the surgery and they don't get an appointment until 2 or 3 weeks' time. So, before it's time for the appointment, for them to go to the surgery, they go, but they are already recovered. If you are already recovered what's the point of going to the surgery?'

Facilitator: 'OK. You say you've never been [to the GP]. If today you were really sick what would you do?'

C: 'I would go to the hospital [laughs].'

(C, male, Democratic Republic of Congo, African focus group)

Parents of young children were most concerned about getting emergency appointments, as again they were used to quick access to a doctor in their own countries. This was compounded, for some, by a lack of knowledge about out-of-hours care:

'For example, if I feel sick now or a child has come back from school because he's sick ... You are taking him as an emergency and they won't take him ... But back home in that situation they will take you ... they will take you there and then even if they won't give you anything [laughter in group].' ( $F$, male, Somali focus group)

'But sometimes you can't even get their professional advice if you really need it. You need to phone before $9 \mathrm{am}$. It's OK to get an appointment if you phone before nine in the morning. If it's after nine then you need to wait 2 days at least. But we don't know when our child is going to be ill! Also there are no services at the weekend and this is a real problem. If it's the weekend you need to wait 'til Monday. Usually my kids get ill on Friday afternoon! [laughter].'

(A, female, Farsi focus group)

\section{Confidence in GPs}

While most responders were happy with the overall care they received from their GP, there was evidence of a lack of confidence in them. GPs were often perceived as not being specialised, having an impact on responders' behaviour:

'... we can't see that they [GPs] are much help when they give medicine or something because they aren't specialised ... They think that you are OK and you think you are not OK ...' (R6, female, Syria, interview)

'[My mother] she prefers the Turkish doctors rather than the doctors in here, I don't know, she maybe thinks they are not good and so she prefers Turkish doctors and there is Turkish doctors in London so she would like to go to London where she can explain herself and she understands the doctor ... I think she thinks, 
how can I say, she thinks they are more clever?' (R8, female, Turkish, interview)

Some responders felt that GPs couldn't have the necessary knowledge to treat the range of illnesses that present to them; others suggested that asylum seekers might present with new and unique illnesses that GPs have not seen before:

V: 'How is it possible for one doctor to treat every kind of illness? For adults, kids, and all. For every kind of illness.'

S: 'My doctor doesn't know anything never mind one thing.'

Y: 'I agree. Should be paediatrics that deals with children.'

( $\mathrm{V}$, male; $\mathrm{S}$ and $\mathrm{Y}$, female, Russian focus group)

'It seems sometimes they don't understand how to treat some illnesses ... sometimes they don't understand simple things we may have because they haven't seen it before.' ( $L$, female, Iranian, Farsi focus group)

'The GP must understand that asylum seekers come from different countries, different climates especially African, so the GP must be advised about tropical disease and if they can learn to diagnose these, if they know something about it, they will be able to stop the disease quickly. When the doctor gives the wrong medication, maybe it's because he doesn't recognise the disease and just gives you something to cool you down then he will go home and look up a book.' (D, male, Republic of Guinea, African focus group)

At times care did not met their expectations; for example, hoping for a referral to secondary care but instead receiving a prescription, or not being given a prescription at all. Several responders found it difficult that you couldn't immediately ask the GP for tests or procedures, for example a scan, as in their home country this would be readily available if paid for:

'She wants a scan and the doctor says it is not necessary.' (R14, female, Sri Lanka, group interview)

Some, particularly in the Russian Federation group, expressed concern that their children had not been immunised for certain diseases, in particular tuberculosis (TB). This was thought to be unprofessional on the part of the GP. It became apparent, during the ensuing discussion, that children are immunised for TB in the Russian Federation at a much younger age than would be normal in the UK. However, parents interpreted the GPs' actions based on knowledge of their own healthcare system.

Many of the asylum seekers had difficulty adapting to or understanding a patient-focused style of consultation. Again, this was particularly apparent with asylum seekers from the Russian Federation:

V: '... the specialist asked me what I thought! Why should he do this? Why ask me what I think, he is the specialist.'

B: 'This happened to me too ... when you go to the doctor's they say what's your opinion of what's wrong with you!'

(V, male; B, female, Russian focus group)

'... the first question the doctor would ask you here in his country is which kind of medicine did you used to take and if I say, for example, I don't know, prescription stuff ... I don't [know] why it is. The doctor's duty is to check you, not to obey you. OK?' (R3, male, Iran, interview)

However, the opposite was also true. Patients expressed a feeling that they were not being treated appropriately because they were asylum seekers:

S: ' ... I was seen by four different doctors in the surgery and I was given antibiotics, antibiotics, antibiotics, and none of them actually touched me to see what was wrong, to examine my throat, where it is sore you know? Not one of them actually touched me ...'

Facilitator: 'What do you think, they gave you that medication, the antibiotics, because they didn't have time to examine you properly or do you think it was because you were an asylum seeker, you mentioned they didn't touch you?' S: 'Yes I think so. That's why they gave me just antibiotics and didn't take time.'

(S, female, Democratic Republic of Congo, African focus group)

The use of computers in the consultation also affected their confidence in the GP:

'The GPS ... trust the computer to make the real diagnosis, they are writing in the computer instead of examining the patient and applying their own knowledge and what they have learned. They trust the computer ... He can't touch you because he is tied to the computer.' 
(D, male, Republic of Guinea, African focus group)

SD: '... I mean she [the GP] doesn't really listen to the other problems, the other health problems. I mean she's not listening well, she's I mean she's ...'

SM: 'She's writing in her computer?'

SD: 'Yes! [everybody laughs]'

(SD, female, African; SM, female, Morocco, women's focus group)

This lack of confidence led some to bypass the GP altogether. For example, if the problem was deemed to be an emergency or requiring a specialist some would go directly to hospital:

'... sometimes it is better to just go to the hospital direct.' (R6, female, Syria, interview)

Two related issues appeared to build asylum seekers' confidence in their GP: seeing the same GP each time they attended the surgery, and feeling that they were respected during the consultation. Seeing the same doctor each time was felt to be important because the doctor then knew their, often complex, medical history:

'So sometimes when I go and see another one [GP] he is not good but after that when I stick with only one who is $\mathrm{Dr}$ [name of GP], he goes with me nicely.' ( $\mathrm{N}$, female, Somalia, Somali focus group)

[Interviewer asks R10 if he minds seeing another doctor when they have his medical record]

R10: 'I know but the doctor have, I think, just 12 minutes to see you and if you have to read everything before from 3 to 5 years, you are here and I think it's ...'

Interviewer: 'So do you find that a problem, you would rather see the same doctor?'

R10: 'Yes, the same doctor.'

(R10, male, Algeria, R9-12 group interview)

Being respected during the consultation often meant being listened to:

'And Doctor [name of GP] is a good doctor, when I go to him he is very good, kind, treats me with respect.' (G, female, Russian Federation, Russian focus group)

'If you go to see a doctor if you are not satisfied you will feel double sick. If the doctor listens and understands you, then that is a help in itself. But if there has been no understanding, it's bad. Even if he just gives you advice you can feel satisfied.' (D, male, Republic of Guinea, African focus group)

However, for some, it also meant being examined by the GP, as that was what they experienced in their home country. As described above, many asylum seekers expected that a GP would examine them physically, and appeared to feel that the lack of a physical examination was associated with their status as asylum seekers. This appeared to reduce their confidence in the GP:

'In my opinion, I thought that European medicine is more developed than our country but when I came here I can see it's different, it's not highly developed. For example, I remember when I was in Kinshasa I went to see the doctor, I explained everything to the doctor, how my son was feeling and the doctor tried to touch my son everywhere to see where the pain was, so when he touched a place that was painful and my son cried then the doctor understood where it was painful, so from there he knows how to prescribe the medicine. But here it's difficult, because here they won't touch my son to see where the pain is. Even me, they don't want to touch me to examine me properly. They won't touch you. The only place they can touch you, if it's a woman, then they can do an examination on the private parts because they have to wear gloves for that. Apart from that they never touch anybody. So I think, well this is my opinion.' ( $\mathrm{T}$, female, Democratic Republic of Congo, African focus group)

For some, it was important that the GP not only listened to them medically, but also understood their situation as asylum seekers:

'Well my doctor, when you know my husband had this accident [she has previously described how her husband was attacked and beaten], she [the GP] was very upset. She was really very upset and sympathetic. She understands everything when I go to her. She listens to me'. [Later in same focus group] 'Honestly, she is a motherly doctor in the sense that she's brought me down to my senses and myself in so many instances ... This is the kind of help I'm saying that if doctors could really understand us from that perspective, we really need this understanding.' (E, female, Zimbabwe, women's focus group) 


\section{Access to specialists}

There was a general lack of experience of accessing a gatekeeper-led system like that found in the UK. Many felt that access to specialists was much easier in their country of origin and preferred to access specialists at the time they perceived there to be a problem:

'In Africa if you are sick you can just wake up and go to see a cardiologist the next day without going through a GP. Or if you need a surgeon the same, you can see him the next day. We don't have the family doctor system like here.' ( $D$, male, Republic of Guinea, African focus group)

'It would be better just to go straight to the specialist at the moment you need it.' (R7, male, Azerbaijan, interview)

Reasons for this included the view that specialists had greater knowledge than GPs and that they were able to initiate tests and other procedures, particularly X-rays and scans.

Responders also felt that there were not enough specialists in the UK, contributing to the size of the waiting lists. The existence of waiting lists was a complete surprise to many of the asylum seekers interviewed. While some thought this might be due to their being asylum seekers, others realised that this was a problem for everyone referred by their GP:

'There is a lack of specialised doctors and I think that there would need to be an increase in the number of specialised doctors so when it's necessary a person can go and consult directly to this doctor.' (R7, male, Azerbaijan, interview)

\section{Medication}

The provision of medication was an issue for many of the asylum seekers, in particular antibiotics and paracetamol. In several countries, antibiotics can be purchased directly from pharmacies:

'In Iran for example people go to pharmacy and just ask for antibiotic and you can buy antibiotic from pharmacy.' (R3, male, Iran, interview)

This led to expectations that antibiotics would also be readily available in the UK, and disappointment when they were not prescribed. Many expected medication, even for minor, selflimiting conditions. There was annoyance when prescriptions weren't issued and that they were expected to buy medicine themselves:

'[GPs] say go to pharmacist and get something yourself. You have to decide for yourself which medicine you need! And also you have to buy it yourself. If you try to get help and advice about this then the doctor and nurse will say "There's no need to have medicine, you will get well on your own. It's just a simple illness". l'm really not happy with this.' (L, female, Iran, Farsi focus group)

There was a lack of knowledge about what was available. Responders referred to medications that they bought at home which were either unavailable in the UK or had a different name. The cost of over-thecounter medication was also an issue for many, particularly when GPs suggested that they should buy paracetamol for children, rather than being issued a prescription for it. Responders also felt that they were often 'fobbed off' with paracetamol:

G: 'For everything they give you paracetamol. Tummy ache - paracetamol. Pain in the head paracetamol. You can't get the right drugs you need - just paracetamol.'

$\mathbf{N}$ : 'Yes even for the stomach - paracetamol.'

(G, female; N, male, Russian focus group)

'They don't give you enough medicine. If we were in Iran we could get enough medications for our kids and for ourselves as well. We spend time going to doctor but then nothing, they don't give you anything, just paracetamol. When they do actually give you medicine, well you need to be dying before they give it to you ...' (A, female, Farsi focus group)

Expectations of being prescribed medication came partly from the experience of previous healthcare systems, but also because in some countries of origin, minor symptoms could easily develop. This appeared to be particularly true for respiratory symptoms:

A: 'But when we get a cold, for kids or for us, if it is not treated in time then you can get an infection. It can be quite serious. And if left to go on then it can become dangerous. I am afraid from asthma. I'm very scared that the children develop asthma.'

L: 'Yes, I know, I am scared also for this.'

(A, female, Iran; L, female, Iran, Farsi focus group)

'There are two kinds of cold, one is not serious and you are trying to deal with it. But you don't know, it could go into asthma. In our country, they are not joking with this, it's serious. But here, it's not taken seriously.' ( $\mathrm{B}$, female, Ukrainian, Russian focus group) 
Health systems in the countries of origin

Official statistics from WHO were later used to build a picture of the health systems in the countries of origin; these were compared with those in the UK, US, and Ireland (Table 2). ${ }^{19}$ Only three countries (Azerbaijan, Lebanon, and the Russian Federation) had higher physician densities than those found in the UK, US, and Ireland. Nowhere had comparable nursing densities. Several countries, including the Democratic Republic of Congo, Afghanistan, Iran, and Sri Lanka, had physician densities of fewer than 1 per 1000 population. Childhood immunisation coverage was below $70 \%$ in Democratic Republic of Congo, Afghanistan, Pakistan, and Somalia, but greater than that observed in the UK, US, and Ireland in many of the remaining countries. In most countries, private spending on health exceeded that of government spending. Exceptions were Algeria, the Russian Federation, and Turkey. In most countries the number of hospital beds per 10000 population was less than that found in the UK, US, and Ireland; notable exceptions were Azerbaijan and the Russian Federation, with 83 and 99 beds per 10000 population respectively. These findings confirmed reports from asylum seekers of systems with a high reliance on privately-funded hospitalbased care, rather than a family medicine community-based system.

\section{DISCUSSION}

\section{Summary of main findings}

This study adds to a growing body of literature on the provision of appropriate health care for asylum seekers and refugees, but also has important lessons for the care for another large minority group: Eastern European migrant workers. Asylum seekers have previous experience of a diverse range of healthcare systems, most characterised by a lack of GPs and direct access to hospital-based specialists. This finding in the current study was supported by official statistics.

Accounts from asylum seekers themselves also highlighted the difficulties that the poor and those from marginalised groups have in accessing health care, even when the statistics indicate reasonable levels of provision; for example, Tamils in Sri Lanka. Such factors appear to present difficulties for them when they encounter a healthcare system with such a strong and well-defined general practice component.

Asylum seekers were generally pleased with the care they received from the NHS. However, areas where they experienced difficulties might be partly explained by previous experience. In particular, these areas related to confidence in the GP and access to hospital-based specialists, high-tech tests, such as X-rays and scans, and medication. The policy of encouraging patient-centred consultations was also problematic, as many expected the GP to take control of the consultation and tell the patient what was wrong. Computers also had an impact on the consultation, with the view that the GP was more interested in the computer than in the patients. Issues of continuity and of being listened to and respected within the consultation were also important. A key issue that came through was that many of those interviewed expected the consultation to include a physical examination, and they equated a lack of direct touch with their being asylum seekers.

\section{Strengths and limitations of the study}

This study was unable to employ a purposive sampling strategy, due to the difficulties in accessing the asylum-seeking population. ${ }^{22}$ The work was conducted at a sensitive time, when the number of deportations was increasing, so participants were reluctant to give too much detail about their asylum status. Thus, only the broadest demographic data were available. Nevertheless, it was possible to recruit individuals from a diverse range of countries. As discussed in a previous report, ${ }^{5}$ the trained focus group facilitators were generally known to the group. All but one interview was conducted through an interpreter and, in some cases, the interpreter was well known to the interviewee. These factors, while enhancing rapport, may also have influenced participants' responses; it was also difficult to gauge if the researchers were getting the interviewees' views or a distilled view from the interpreter.

Using members of the asylum-seeking community to act as focus group facilitators in the first study meant that focus groups could be conducted in participants' own language, without the need for interpreters. However, the facilitators required significant training and ongoing support, making this a time-consuming process. This process also led to unintended consequences for those acting as group facilitators, such as being viewed with suspicion by members of their community. ${ }^{22}$ Thus, the second study used one-toone semi-structured interviews, conducted through an interpreter where required. On two occasions interviews were conducted with a group: one with three members of a family; the second with four individuals who knew each other. The lack of interaction between the participants, and the presence of the interpreter, led the dynamic of these to be more a series of linked interviews rather than the sharing of experiences and opinions that one would expect of a focus group. This led the 
researchers to define these as group interviews, rather than focus groups.

The use of WHO statistics to build a picture of the healthcare system in each country, linked to the accounts of asylum seekers themselves, brings a new dimension to this type of work. It illustrates the diversity of healthcare systems in operation, but also gives a reminder that universal access to health care is not a guarantee, even in countries that, on paper, appear to have a relatively wellestablished system.

\section{Comparison with existing literature}

Previous studies have shown that prior experience can have an impact on expectations: a lack of awareness of appointment systems, expectations of high-tech medicine such as MRI, and access to antibiotics have all been reported. ${ }^{5,12-15}$ However, these studies did not attempt to link the views of the participants to the structure of the healthcare system that they came from. This study adds to that knowledge and explores further some of the issues that may be amenable to change, if GPs and other primary care staff are aware of the reasons for these views. For example, asylum seekers from the Russian Federation were critical of GPs for not immunising their children against TB, which influenced their overall confidence in GPs. This view is easier to understand when set against the differences in TB prevalence (in 2004 Russian Federation: 160 cases per 100000 population; UK: 9 cases per 100000 population) and the knowledge that, in the Russian Federation children receive their first $B C G$ vaccination within 14 days of birth. ${ }^{23}$

The desire for immediate appointments and for medication was driven not only by prior system experience, but also by the fear of symptoms becoming more dangerous, especially in children. Again, this is understandable when viewed in the context of the types of diseases that are prevalent in many countries of origin, including TB, measles, and diarrhoeal diseases. ${ }^{21}$

Interviewees spoke of a lack of confidence and trust in their GP, influenced by their view that GPs are too generalist but also by other issues such as GPs' lack of human touch and their reliance on computers. This suggests that asylum seekers are no different from other patients in seeking a patientfocused approach, centring on the holistic aspects of general practice. ${ }^{24,25}$ However, if GPs are particularly aware of the negative effect that using a computer or not physically examining a patient may have on the level of trust that the asylum-seeking patient has in the GP, then they can take steps to alleviate those concerns.

Trust could also be built by GPs ensuring that they engage with and listen to the patient, even if the main issue is not health related. The author Mechanic suggests that there are five aspects to trust, including trust in the doctor's technical and interpersonal competence, trust in the doctor's control over patients' access to health care, and trust in open communication and disclosure. ${ }^{16,18}$ The present study confirms that asylum seekers often come from countries with ready access to specialists and that they struggle to understand why GPs will not refer them on to specialist services. ${ }^{5}$ However, if GPs foster and build on the level of trust engendered within individual consultations - through respect and listening to and examining patients - the rapport they develop may give their asylum-seeking patients the confidence to trust them when the consultation does not result in a prescription or referral.

\section{Implications for clinical practice}

GPs and other healthcare professionals would benefit from more information about the healthcare systems that asylum seekers and other migrants are used to and the way their countries of origin can influence their expectations of health care here, such as previous direct access to specialists in hospital or to antibiotics, or lack of appointment systems. This is particularly pertinent for individuals from countries that do not have a gatekeeper system for access to specialists, such as is found in the UK. Asylum seekers' apparent difficulties with care may well be due to a lack of understanding of the role of GPs. The NHS should explore new ways of explaining this system to them, for example using established refugees as service advocates.

Ready sources of information are also required for GPs and other healthcare professionals, including, for example, access to information on disease prevalence or immunisation practices in other countries. This will give them the background information they require to help justify clinical decisions here. Healthcare professionals must also realise that some situations, for example the provision of paracetamol, require greater understanding from themselves, with seemingly inexpensive over-the-counter medications often unaffordable to asylum seekers. The current emphasis on involving the patient in the consultation and decision-making process may also need to be handled with more care, if it is not to result in decreased confidence in the GP. Finally, building trust and rapport within the consultation, for example by physically examining patients when possible or explaining why an examination is not required, may also help to counteract unmet expectations within the consultation. 


\section{Funding body}

The focus group study was funded by the Scottish Executive Health Department. The interview study was funded by the Chief Scientist Office, Scottish Executive Health Department (CZG/2/165). The views expressed are those of the authors and not necessarily those of the funders or their employers

\section{Ethical approval}

The focus group study was approved by the NHS Greater Glasgow Community/Primary Care Research Ethics Committee (reference no 1/03). The interview study was approved by the NHS Greater Glasgow Primary Care Division Research Ethics Committee (reference no 05/S0701/2)

\section{Competing interests}

The authors have stated that there are none

\section{Acknowledgements}

We wish to thank Catherine McNeill and Michere Beaumont for transcribing the data; Rose Barbour for helpful support with the focus group training; Rafik Gardee, Angela King, Anne Douglas, Ann McDonald, and Ruby Sloan for their support and knowledge during the focus group study; Colin McGavin of the Scottish Refugee Council, Mary Hill, Jassim Johe, and HomeStart for facilitating access to asylum-seeking groups. Finally, we particularly want to thank the five members of the asylumseeking community in Glasgow for acting as focus group facilitators and for their invaluable help: Allah Nawaz Rustamkhail, Mercy Kamanja, Londi Luyeye Beketch, Jean Kabongo, and Nasa Sean Murray.

\section{Discuss this article}

Contribute and read comments about this article on the Discussion Forum: http://www.rcgp.org.uk/bjgp-discuss

\section{REFERENCES}

1. Home Office. Asylum statistics United Kingdom 2006. London: Home Office, 2007. http://www.homeoffice.gov.uk/ rds/pdfs07/hosb1407.pdf (accessed 29 Oct 2008).

2. Department for Work and Pensions. National insurance number allocations to overseas national entering the UK 2006/07. London: Department for Work and Pensions, 2007. http://www.dwp.gov.uk/asd/asd1/niall/nino_allocation.asp (accessed 23 Oct 2008)

3. Audit Commission. Crossing borders. Responding to the local challenges of migrant workers. London: Audit Commission, 2007. http://www.audit-commission.gov.uk/Products/NATIONALREPORT/05CA5CAD-C551-4b66-825E-ABFA8C8E4717/ CrossingBorders.pdf (accessed 29 Oct 2008).

4. Starfield B, Shi L, Macinko J. Contribution of primary care to health systems and health. Milbank Q 2005; 83(3): 457-502.

5. O'Donnell CA, Higgins M, Chauhan R, Mullen K. 'They think we're OK and we know we're not'. A qualitative study of asylum seekers' access, knowledge and views to health care in the UK. BMC Health Serv Res 2007; 7: 75. http://www.biomedcentral.com/ content/pdf/1472-6963-7-75.pdf (accessed 29 Oct 2008)

6. Jackson JL, Chamberlin J, Kroenke K. Predictors of patient satisfaction. Soc Sci Med 2001; 52(4): 609-620.
7. Hooper R, Rona RJ, French C, et al. Unmet expectations in primary care and the agreement between doctor and patient: a questionnaire study. Health Expect 2005; 8(1): 26-33.

8. McKinley RK, Stevenson K, Adams S, Manku-Scott TK. Meeting patient expectations of care: the major determinant of satisfaction with out-of-hours primary medical care? Fam Pract 2002; 19(4): 333-338.

9. Thompson K, Parahoo K, Farrell B. An evaluation of a GP out-ofhours service: meeting patient expectations of care. J Eval Clin Pract 2004; 10(3): 467-474.

10. Little P, Dorward M, Warner G, et al. Importance of patient pressure and perceived pressure and perceived medical need for investigations, referral, and prescribing in primary care: nested observational study. BMJ 2004; 328(7437): 444-446.

11. Bowling A, Redfern J. The process of outpatient referral and care: the experiences and views of patients, their general practitioners, and specialists. Br J Gen Pract 2000; 50(451): 116-120.

12. Levenson R, Coker N. The health of refugees. A guide for GPs. London: King's Fund, 1999.

13. Lipson JG, Weinstein HM, Gladstone EA, Sarnoff RH. Bosnian and Soviet refugees' experiences with health care. West J Nurs Res 2003; 25(7): 854-871.

14. Lawrence J, Kearns R. Exploring the 'fit' between people and providers: refugee health needs and health care services in $\mathrm{Mt}$ Roskill, Auckland, New Zealand. Health Soc Care Community 2005; 13(5): 451-461.

15. Hudelson P. Improving patient-provider communication: insights from interpreters. Fam Pract 2005; 22(3): 311-316.

16. Mechanic D. The functions and limitations of trust in the provision of medical care. J Health Polit Policy Law 1998; 23(4): 661-686.

17. Fugelli P. Trust — in general practice. Br J Gen Pract 2001; 51(468): 575-579.

18. Mechanic D. In my chosen doctor I trust. BMJ 2004; 329(7480): 1418-1419.

19. World Health Organization. World health statistics 2006. Geneva: World Health Organization, 2006. http://www.who.int/whosis/whostat2006.pdf (accessed 29 Oct 2008).

20. Ritchie J, Spencer L. Qualitative data analysis for applied policy research. In: Bryman A, Burgess RG (eds). Analyzing qualitative data. London: Routledge, 1994: 173-194.

21. Glaser BG, Strauss AL. The discovery of grounded theory: strategie for qualitative research. London: Weidenfeld and Nicolson, 1968.

22. Higgins M, O'Donnell CA. Involving refugees in focus group research. In: DeSouza R, Williamson A (eds). Researching with communities: grounded perspectives on engaging communities in research. Auckland: Muddy Creek Press, 2007; 167-180.

23. Drobniewski F, Balabanova Y, Zakamova E, et al. Rates of latent tuberculosis in health care staff in Russia. PLoS Med 2007; 4(2): e55.

24. Scheppers E, van Dongen E, Dekker J, et al. Potential barriers to the use of health services among ethnic minorities: a review. Fam Pract 2006; 23(3): 325-348.

25. Mercer SW, Cawston PG, Bikker AP. Quality in general practice consultations; a qualitative study of the views of patients living in an area of high socio-economic deprivation in Scotland. BMC Fam Pract 2007; 8: 22 . 